\title{
Oh, kes saab lihakeelega üles rääkida taevased asjad!
}

\author{
Mart Saali illmutus
}

$\underline{\text { Kristi Salve }}$

Kes otsib, see leiab. Muidugi. Veel enam - otsija leiab ka seda, mida ta poleks teadnudki otsida. Vahel ehk ainult viimast. Aga kes ütleb, et see, mida meie oskame otsida, on üldse parim?

Kümmekond aastat tagasi sattusin üht Eiseni rahvaluulekogu lehitsedes ja ei mäleta enam mida otsides ühele oma suurimale leiule.

Tol ajal olin juba huvitatud vennastekoguduse vaimsest pärandist. Olin lugenud sellekohast kirjandust ja püüdnud ülevaadet saada Kirjandusmuuseumi arhiivides säilitatavaist käsikirjadest. Neid, kas siis lihtsaid, väheldase mahuga vihikuid või enam-vähem kogukaid, vahel koguni nahkköites käsikirjalisi raamatuid on nii Eesti Rahvaluule Arhiivis (ERA) kui Eesti Kultuuriloolises Arhiivis (EKLA) kümnete kaupa. Juhuslikult võib vanu vennaste käsikirju paikneda ka ERA suulist pärimust sisaldavates kogudes, nagu siin järgnevalt publitseeritav, M. J. Eiseni kogust pärinev tekst. Hoopis rohkem leidub rahvaluulekogudes ootuspäraselt suuliselt edasi kandunud jutustusi velistest ja nende laule.

Rudolf Põldmäe töö vennastekoguduse ajaloo uurimisel on seniajani olulisim. Peale üksikküsimustele pühendatud artiklite on ta kirjutanud ülevaate hernhuutlikust kirjasõnast, kus käsitletakse trükiste kõrval ka vennaste käsikirjalist pärandit (Põldmäe 1965). See on hea algteadmiste andja ja teejuht edaspidisteks uuringuteks ning põhineb autori asjatundlikkusel. Kõrvale võib jätta ilmumisajal valitsenud ideoloogiast ja võib-olla ka autori enese ratsionalistlikust, uurimisainega haakumatust meelelaadist tingitud hinnangud. Ainult peajooni andvas käsitluses on aga - ehk paratamatultki - puudutamata jäänud haruldasemad zhanrid, muuseas ka nägemuste üleskirjutused, mis koos elulugude ja prohvetikuulutustega moodustavad ometi sisuldasa veliste vanade käsikirjade algupärasema ja huvipakkuvama osa. Tähelepanuväärsete usuinimeste kohta käivaid isikuloolisi pärimusi, samuti nende nägemuste ja prohvetlike kuulutuste ümberjutustusi - enamasti omavahel mitmel moel põimunult - kohtame siiski palju suuremal määral suulises traditsioonis. Samal ajal pole sajandipikkuse suulise leviku läbi teinud ilmutus enam ainult selle väidetava nägija, vaid ka iga edasijutustaja usuliste kogemuste peegeldus, mistõttu väheste vahetute kirjapanekute tähendus on väga suur.

Vähemalt Mart Saali ilmutus, nagu ka Lüütsepa Jaani oma, on vaieldamatult protestantlikpietistlik. Tähelepandav on selle Kristuse-kesksus. Peale Jeesuse märkab nägija veel paaril korral ingleid. Pole võimalik täie kindlusega öelda, kui vana selline seadumus oli. Varasematel sajanditel fikseeritud maagilistes tekstides võib küll korduvalt täheldada pöördumisi Maarja ja pühakute poole, samuti kaebavad mitmed autorid «ebausu» üle, mis väljendus muuseas katoliiklikust perioodist pärinevate pühapaikade ja pühakute mälestuspäevade austamises (vt näiteks Laugaste 1963: 30, 37, 55-56, 60, 69). Kui Saksamaal ja Skandinaavias on võimalik jälgida, kuidas kiiresti, lausa ühe inimpõlve jooksul pärast reformatsiooni asenduvad ilmutustes pühakud ja Maarja inglitega (vt J. Beyeri kirjutist samas kogumikus lk 62-82), siis Eesti kohta pole 16.-17. sajandist vastavat autentset materjali. Maagilised tekstid võivad oma vormellikus tardumuses edasi kanda religioosseid igandeid, samuti võib mõni kombestikuelement säilida pelgalt traditsiooni jõul. Ilmutus, kuigi samuti traditsiooniga seotud, on seda rohkem n-ö horisontaaltasandil, vastates põhijoontes oma aja elavale usule. 
Tõenäoliseks võib ikkagi pidada seisukohta, et alles vennastekogudus vastandus selgelt poolpaganlikule katoliiklikule sünkretismile, mis elas edasi pealispindseks jäänud evangeelse usu katte all.

Siinne tekstipublikatsioon koosneb kahest osast: J. Oidermanni saatesõnast ja Mart Saali nägemusest tema enese kirjapanekus. Palju huvitavat, sealjuures nii traditsioonilist kui erakordset leidub juba saatetekstiski. Võtkem näiteks nutva väikelapse muutumine vagusaks taevatähtede nägemisest või siis nekrutite püüdmine, mis on meie ajaloolises rahvatraditsioonis vägagi viljeldud teema. Õnnelik pääsmine sünnib kas juhuse tõttu, mis on nii uskumatu, et sunnib seetõttu eeldama kõrgemate jõudude sekkumist, või siis on üleloomulikud tegurid ka avalikuks tehtud (vt nt otsijate silmade sõgestamist nõidprohveti poolt Salve 1998: 75). Igatahes võib saatesõnast, mis ju on õigupoolest lühike elulooline ülevaade, aimu saada Mart Saali tavatult erksast psüühikast, see aga on kindlasti visionaarsuse üheks eelduseks.

Avaldatav nägemus on paralleeliks R. Põldmäe artiklis 63 aastat tagasi avaldatud Lüütsepa Jaani nägemusele, mille originaali (ja selle järgi ka artikli) pealkiri sisaldab määratlust ello käük, st elulugu (Põldmäe 1937).

Umbes samavõrra on biograafilisi teatmeid Mart Saali käsikirjas, mille saatja J. Oidermann on põhjendatult nimetanud ilmutuseks, sest valdava osa selle mahust moodustab ilmutuse või nägemuse üleskirjutus. Biograafilised märkmed paiknevad ju õigupoolest irdosana käsikirja lõpus.

Tegelikult on lõppe mitu: esimesega lõpeb jutustus nägemusest ja pärast kinnitussõnu «aamen» ja «halleluuja» järgneb eelnevaga kaunis vähe seotud manitsus, mis omakorda lõpeb Jeesuse ristil lausutud sõnadega «See on lõpetud». Seejärel tulevad eluloomärkmed, mis oma napisõnalisuses meenutavad sissekandeid perekonnapiiblisse. Manitsus ja eluloomärkmed on ühel, erinevast paberist, lehel. Ka tint, sulg ja käekiri on erinevad. Kui eluloomärkmetes viimasena nimetatud aastaarv on õigesti välja loetud, siis on see leht kirjutatud võibolla juba mitu aastat enne ilmutuse nägemist. Hiljemalt köitmisel on Mart Saali käsikirja nägemuste osa lehed segamini läinud, deshifreerimisel on püütud taastada nende õige järjekord.

Nii Lüütsepa Jaani kui Mart Saali nägemused on nähtud raskelt haigena, elu ja surma piirimail, võib-olla koguni kliinilise surma seisundis, esimene ainult 15 aastat varem ja Võrumaal. Kui nende kirjapanekuid kõrvutada, siis võib täheldada, et Lüütsepa Jaani nägemus on dünaamilisem ja meeldesööbivate piltide poolest rikkam. Lisaks sisaldab ta huvipakkuva laulu, kus esineb nii regivärssidele kui vennaste lauluvarale omaseid elemente ja mis on püsinud enam-vähem tänini suulises traditsioonis nn värsikesena (vt Salve 1996).

Mart Saali nägemuse kirjapanekus on konkreetsete teise ilma piltidega võrreldes arutluste ja manitsuste osakaal mahult tunduvalt suurem. Niisugune asjaolu viitab võimalusele, et ilmutus on kirja pandud alles pärast paljusid suulisi esitusi kodus omastele ja külalistele, vennaste palvetundides ja mujal, sest vaatamata mitmekordsetele kurtmistele «liha keele» võimetuse üle, pole ilmutuse ümberjutustus sugugi kobav ega napisõnaline, vaid vägagi voolav. Selle laad pole kaugeltki kaine ja pelgalt protokolliv, hoopis vastupidi - jutustuse keelekasutus on hoogne ja osutab ühtlasi, et eesmärgiks pole tühi ajaviide, vaid inimeste meeleparandusele kutsumine.

Kogu kirjapaneku kestel tuleb esile lihaliku keele ja vaimus nähtud taevalike asjade vastandamine, konkreetselt esimese põhimõtteline piiratus ja selle ületamise ponnistused, tuntud juba Piibli prohvetiraamatuist. Piiblist on tuttavad ka paljud Mart Saali konkreetsed näge- 
muspildid - õigete ja hukkamõistetute käekäik teises ilmas, kuke laulmine, vagade valged riided, kitsas ja lai tee, uus Jeruusalemm, Jeesuse ja uskliku vahekorra kujutamine peigmehe ja pruudi vahekorrana jne. Piibli hea tundmine peaks olema tema kui vennastekoguduse liikme puhul eelduspärane, ja selle paikapidavust kinnitab ka perepärimus (vt allpool J. Oidermanni saatesõna), kuid teisalt on täiesti võimalik, et need ja sellesarnased pildid on meelde vermitud Bunyani «Palveränduri teekonna», vennastekoguduse ühe lemmikraamatu, samuti lauluraamatute ja muu vaimuliku kirjanduse vahendusel.

Teise ilma, taeva ja põrgu nägemine oli üldine ka 19. sajandi alguse taevakäijate liikumises. Kahjuks on teated taevakäijate nägemustest, mis on kokku võetud R. Põldmäe artiklis, jõudnud meieni kas läbi pikemaaegse suulise leviku või siis ajaliselt lähemate, kuid enamasti ebaobjektiivsete kirjalike allikate kaudu, milles on püütud ilmutusi ja nende nägijaid naeruvääristada või lausa karistusväärsetena kujutada (vt. ratsionalistidest kirjameeste ja pastorite tunnistusi Põldmäe 1935, samuti kohtuaktides leiduvaid andmeid Sild 1935). Muidugi võib tõenäoliseks pidada, et ajas ja ruumis tihedalt koondunud taevakäijate nägemused moodustasid omavahel konkreetsete detailide poolest rohkem seotud kogumi, kuna nii Lüütsepa Jaan kui Mart Saal on iseseisvamad.

Üks ilmutustele väga omane motiiv on veel rõhutamine, et kõike nähtut/kuuldut ei tohi avaldada (vrd $2 \operatorname{Kr} 12: 2-4)$. Vahel on see konkretiseeritud: rääkida küll lubatakse, ainult kolme sõna keelatakse kõnelemast; keelu rikkumise puhul on sanktsiooniks surm (vt EStK XXXIV, 18/9 < Ksi; RKM II 83, 151 (8) < VMr; RKM Mgn II $3523<$ Vas).

Nagu J. Oidermanngi märgib, oli Mart Saali kirjutamisoskus täiesti iseõppimise teel omandatud, mis oli tavaline ajal, kui rahvakoolide võrk ei katnud kogu maad või kui koolis kirjutamist ei õpetatud. Vennastekoguduse traditsioon on muide tundnud ka kirjaoskuse omandamist ime läbi, näiteks inglite sõna peale (Põldmäe 1935: 167). Mart Saalile olid küll perekonnapärimuse kohaselt eeskuju andnud (tol ajal loomulikult vanas kirjaviisis) raamatud ja küllap sealsete vennaste hulgas ringelnud varasemad käsikirjadki, kuid kui eeskujud isegi olid keele ja ortograafia poolest ebajärjekindlad, siis mida võib tahta veel nende järgijast! Allpool toodud faksiimilele pilku heites peaks mõistetav olema, et selle väljalugemine nõudis tublisti aega, ja eksitusi võib ikka sisse jäänud olla.

Tundus otstarbekas minna erinevat teed sellest, mida R. Põldmäe on kasutanud Lüütsepa Jaani nägemuse publitseerimisel. Arvan, et diplomaatiline äratrükk pole kõige parem lahendus juhul, kui ühelt poolt on usutav, et pikema vaevanägemise tulemusena olen mitme inimese kaasabil suutnud - ehk ebaoluliste eranditega - välja lugeda selle, mis oli Mart Saalil mõttes, ning kui teiselt poolt on karta, et nii mõnelegi lugejale oleks kõikuva, et mitte öelda puuduva ortograafiaga, sõna- ja lausepiire tunnistamata kirja pandud nägemuse kokkuveerimine liiga vaevaline töö. Nii huvitav tekst väärib ometi rohkem lugejaid, ning oleks tõsiselt kahju, kui tehnilised raskused nende arvu vähendaksid! Sellepärast ongi käesolevaga lugejale pakutud siin faksiimilena mõned leheküljed ligemale 200-aastasest käsikirjast (täieliku faksiimileteksti võib leida e versioonist), teiseks aga selle väljaloetud ja redigeeritud kuju. Vana kirjaviis on sealjuures asendatud uuega, ortograafia ebajärjekindlusi õgvendatud, tänapäevastatud kokku- ja lahkukirjutamist ning interpunktsiooni. Säilitatud on mõningaid koloriiti andvaid murdepäraseid ja/või arhailisi jooni, näiteks $o$ järgsilpides, lühikesed tud-kesksõna vormid, adverbisufiks -ste (pro -sti) jne. Juhul, kui on karta mõne sõna valestimõistmist või mõistmatajäämist, on kohe selle järel nurksulgudes seletus. Paari kohta, mille väljalugemine oli väga raske, on markeeritud nurksulgudes küsimärgiga. 
J. Oidermanni rohkem kui sada aastat hiljem kirja pandud saatesõna tundus olevat otstarbekas avaldada originaalkujul, sest tema ortograafia on kindlasti üldmõistetav, kuigi järjekindlusetust ju esineb. Niisugune talitusviis on uuemate ja arusaadavamate käsikirjade puhul tavaline, kusjuures interpunktsiooni siiski korrigeeritakse. Paar problemaatilist kohta on seotud lõpetamata lausetega, mis näivad tulenevat kirjutaja mõttelünkadest. Nende täitmisest on loobutud.

Nagu selgub saatesõnast endast, oli J. Oidermann nägemuse nägija pojatütre mees, nii et seal toodu pärineb oma perekonna traditsioonist ja sellel on n-ö usaldusväärsuse garantii.

Eesti Rahvaluule Arhiivis säilitatakse kokku veel umbes 250 lk J. Oidermanni (kelle eesnimegi pole kahjuks seni õnnestunud avada) enda kirjapandud mitut liiki rahvapärimusi, mis ta on saatnud M. J. Eisenile 1923. ja 1924. aastal. Selle materjali seas leidub nii ehedat traditsiooni kui ka üleskirjutaja töötlusi või lausa omaloomingut. Mart Saali ilmutuse kirjapaneku jõudmise eest Eesti Rahvaluule Arhiivi ja sedakaudu nüüd ka rohkemate lugejate kätte väärib ta kindlasti enim tänu.

Tänan lõpuks omalt poolt Anne Türnpud, Silja Härmi ja Arvo Krikmanni kaashuvi ning abi eest.

\section{Kirjandus}

Laugaste, Eduard 1963. Eesti rahvaluuleteaduse ajalugu I. Tallinn

Põldmäe, Rudolf 1935. Taevakäijad. Kaleviste mailt. Tartu, lk 123-176.

Põldmäe, Rudolf 1937. «se velle Lütseppa Jani ello käük siin ma pääl ehk sääl taivan.» Eesti

Kirjandus, nr 12, lk 611-618.

Põldmäe, Rudolf 1965. Hernhuutlik kirjasõna XVIII sajandil ja XIX saj. algul. Eesti kirjanduse ajalugu. I köide. Tallinn, lk 205-228.

Salve, Kristi 1996. Estnische geistliche Verse. Congressus Octavus Internationalis FennoUgristarum Jyväskylä 10.-15.8. 1995. Pars 6. Ethnologia \& Folkloristica. Jyväskylä, lk 379-383.

Salve, Kristi 1998. Kordo - nõid ja/või prohvet. Mäetagused, nr 8, lk 58-79.

Sild, Olaf 1935. Üksikasju taevakäijate liikumisest mõningate säilinud kohtuaktide valguses.

Usuteadusline ajakiri, $\mathrm{nr}$ 4, lk 109-120.

\section{Mart Saali ilmutus}

Mart Saali isa Rüüts Jaak (sel ajal ei olnud veel liiganimesid) elasid Tori kiriku ligidal. Koha nimi oli Väljaotsa. Ta oli selleaegse talu hoonete ehitaja. Kui poeg Mart sündinud, kui laps 6 nädala vanune, on vali ema ta nutmise pärast vitsaga last peksnud.

Isa, kes poja nutmist meel ärdaks saanud, ütelnud: «Sina võritabaline, sa nenda viisi peksad last!» 
Võtnud lapse oma sülle, viinud õue ja näetanud taeva tähti. Peale selle pole laps ilmaski enam nutnud.

Kui ta nekruti ealine olnud, põgenenud metsa ja peale selle tulnud kodu leiba otsima. Isa petatanud ta ära tua laale õlgede riida ala ja löönud pitka vitsaga katuse alt nõres tahma õlevirna peale. Pea tulnud ka otsijad, ladunud õled ära, aga 3 kubu jätnud, et nende all enam ei ole, ja läinud minema. Isa küsinud pojalt: «Kas sa ei kuulnud, kui sind otsiti?» Ta vastanud: «Pole midagi kuulnud, ma magasin.» = 1800. a.

Isa majast tulnud Mäelt Marti talusse elama ja talu tütre omale abikaasaks üürikeseks aigaks. Suri esimene abikaasa ära, siis võtnud teise Mäelt Mardi tütre. Sellega on temal ka lapsi olnud. Selle noorema eluaja sees tulnud kiusaja viin, et mõisates palju viina aeti. Kord saanud nii joobnuks. Ta olnud väljas oma jootavad olekud välja magamas, aga see eksitus, mis teda oli vaevanud tal nendel tõutus. Omas meeles isienese üle tõeste ei joua inimene valitseda.

Ta täitnud tõutuse kindlast kuni surmani, viina ei ole enam pruukinud. Ta oli vennaste koguduse liige ja kindel usumees. Ikka, kui vähegi aega olnud, siis ikka lugenud Piiblit. On ka lugemist küla rahvale ette lugenud. Tema Taevalik ilmutamine olnud Mäelt Mardil 5mal Jõulukuu päeval 1807. (See vana Heft on ta oma käekiri. Koolisi ei olnud, siiski vahva tahtmisel on trüki tähtede vormi tähel pannes ja kirjutama püidnud saama.

Teine naine surnud tuhuvoodise. Ka vaesed lapsed jäenud. Selle hädas võtnud Tiidu talust tüdruku, kes Aasu külast pärit ja kohtu sundimisel pidi Tiidu talus teenima, 18 a. vana. Sellega olnud 12 last, nende hulgas ka minu äi Mart Saal.

Minu äia isa on sündinud 1779 ja suri 1846.

Sündimise ja suremise päev on 25mal Märtsil.

E 53892/3 (6) < Tori khk, Lõusa - J. Oidermann (1924).

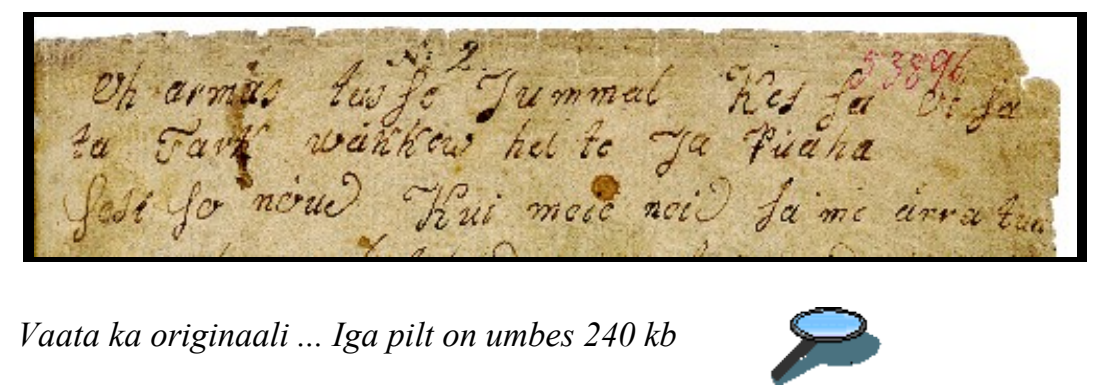

Oh armastuse Jumal, kes sa otsata tark, vägev, helde ja püha, sest so nõud, kui meie neid saame ära tunda, on imelikud. Missugust teed sa meiega, oh Jumal, võtad käia. Sest seda tunnen ka mina ja tahan Kristuse sees väga rõõmsaste tänada, kui ma omas surmas so imelikku abi sain tunda. 
Armsad vennad, ärge pange imeks, kui ma nõdruse sees midagi rääkisin, sest mulle sündis ilma mo mõtlemata raske haigus. Ja see oli nõnda, kui meil oli 1807. aasta ja 5. jõulukuu päe, et ma jäin õiete väga raskeste aigeks, nõnda et ma ühtigi omast valust ei tea, kas ma siin ilma peal olin ehk olemata.

Ja see sündis 11. jõulukuu päeval, õhtul, et ma hakkasin rasket hingevalo, lõpmata häda tundma, mis südame ja hinge peale nõnda käis kui tuli, ja ma olin pooleni ööni kui raske aige. Aga see sündis, kui kukk laulis, et ma jäin kui surnud. Ja veel enne kui mo naine mo juurde tuli ja ütles ja küsis, et: «Sa nüüd akkad jo surema, kas sa mind jätad?» Ja ma ütlesin: «Ei meie ühe hoobiga kõik ei sure, palu aga Jumalat ja kasvata lapsed targaste.»

Laskem, vennad, nüüd vaata, mis sünnib. Nüüd ma jäin kui surnud. Ma tundsin ennast tõeste, et ma olin kui surnud. Nüüd läksid vaimu silmad lahti [?].

Nüüd lõppes otsa. Ja nüüd oli maailm ja sellega kõik häda ja valu ja kõik, mis muret teeb, otsa saanud. Ma tundsin, et mu vaim nägi ennast ihust ära lahotud olevat. Ma sain oma silmaga ja oma kätega Kristust otsekui katsuda. Ta oli otsekui inimene, aga tõesti kui Jumal. Ja jumaliku väe valguse, lõpmata rõõmu ja igavese õnnistuse sees ma olin ühtlaisi Kristusega. Ma nägin ennast kui pruudi peiule valmistatud olevat. Ma jäin pea nõdraks, ja siis ma tundsin Kristust enese peale kui vaimoga puhuvat, ja siis ma tundsin ikka jälle uut vaimolikku väge.

Ma nägin ennast muudetud olevat. Ma nägin oma iho, kuida teda ära seletati. Ta hakkas selgeks minema, ta oli patust puhtaks saanud, ta paistis läbi otsekui laas [= klaas] ja akkas selgeks minema peast seni kui jala tallani. Kõik patt ja eksitused, need langesid ikka alaspidi seni kui viimse jala varvani välja. Ei seal olnud kuu ei päeva, ei tähtide valgust, sest Jumala au, mis isi valgus oli, valgustas kõik, kus vasto päike must ja pime on oma valgusega.

Ma nägin kohe, et mo patud olid andeks antud. Neid oli ühe kõrge kibi mäe külge risti poodud. Ma nägin põrgutee, mis lai ja suur, tasane ja ilus, ja selle suure värava, mis kui linna kummitud värav oli ja jäi vasakule poole 1 ehk 2 vagu maad meist maha. Sealt käis nii kange külm hoog, mis ei või rääkida. Ma nägin taeva tee. See oli küll esmalt kitsoke, mägiline, orgline ja näitas vaevaline käia, aga ta läks ikka paremaks ja oli viimaks õige rõõmus.

Ma nägin Kristust otsekui inimest ta palesse. Seal oli lõpmata au, mis ei või ära mõista ega üles rääkida. Ma kuulsin ingli pasuna, mis ühte järgi hüüdis, aga nende nägu ei või ma mitte üles rääkida. Ma nägin kohto paigad tihti, kus noomiti, mikspärast patust ei pööra, mikspärast ei uso Moosest ja prohvetid, mikspärast pühad kirjad ei uso. Ma sain teada, et see suur kohto paik veel ees oli. See üeldi ühe järve ääres olevat; aga surma ja hukkamõistmist ei olnud mul ei igavesti änam karta. Seält üeldi kui sild üle minevad, ja seal siis üeldi veel armastuse side ümber pandavat ja siis taeva pulmile minevat. Neid paiku ma ei näinud. Nõnda, vaata, ma olin ikka Kristusega, ma ei olnud mitte maa peäl, ei ma näinud ennast mitte taevas olevad. Ma ei olnud mitte ei kellegi asja ega alose peäl, nõnda kui vaimol ei ole ühtegi tarvis. Ma nägin ennast aga Jumala armastuse sees, kuho päikest tarvis ei olnud valgustama. Ja jälle ma olin Jeesusega kui abimehe ja vennaga, kui pruut oma armsa peioga. 
Nüüd meie tulime jälle maha poole otse kui mängides ja tantsides, Jeesus, ja üks kui kolmas oli ka, nemad olid kui inimese näol. Ma kuulsin jälle taeva mängid, mis magusad Jumala armastuse annid, mis, kui see apostel räägib, mis kõrv ei ole kuulnot, mis ühegi silm ei ole näinud, mis ühegi keel ei või üles rääkida, mis ühegi süda ei ole maitsta saanud, nenda ma nägin ikka uued asjad, mis minagi oma meelega ei või ära mõista ja ei ka üles rääkida. Ma olin ikka Jeesusega, ma tundsin teda, et ta oli see Jeesus.

Oh armsad vennad, kui väga magus elo on see, kui meie oma armsama armastajaga ühemeelelist elo elame. Mis see siis, mõtlen mina, mino armsad, peaks olema, kui meie näeme ennast Jeesuse seltsis oma silmaga ja oma kätega teda katsume! Mis armsad elo õnnistused, mis liha keel siin ei või üles rääkida, mis jumalikud uued taevased asjad, mis kallid inglite laulud, mis Jeesust palest palesse vaatama - oh rõõmo, mis hing seal tunneb, kus tema patu kiusatusest lahti näeb ennast olevat, mis see julgus ja raho hinge sisse igavest õnnistust peab valama, et raho ja lahti kõigist pato võlast... Mis see veel peab olema, et Sul Jeesuse läbi ja Jeesuses Jumalaga igavene õnnistud raho on. Oh magust armastust, mis südant parako veel une sees peab liigutama.

Oh peaks ma inglite keelega saama rääkida, ei siiski ma ei jõuaks neid asju ära rääkida, mis ma olen näinud. Sest ei ma näinud ühtegi asja maapäälste asjade näo järele, sest kõik oli hoopis teistviisi, mis silm ei ole eal elades näinud, mis maapäälste asjade ega kuninglikugi au riistadega ühte ei sünni.

Et vaata nüüd, ma nägin ennast jälle ei mitte kui ihu silmadega, vaid jälle kui vaimo viisil väga paljo rahvaga. Ei ma näinud mitte, et nende pääle kohut mõisteti. Nemad olid nagu üks Jumala pererahvas. Ma nägin neid kõik usuriides olevat, mis ma ei või ära mõista ega üles rääkida. Ma nägin kõikesugu rahva seast neid olevat. Nemad olid vaimud ja inimeste hinged. Ma nägin Jeesust enesest nagu eemale minevat ühte teise paika. Ma jäin siis üksi nagu ilma seltsita ja ilma abimeheta. Ma üksine ei osanud minna kuhogi poole. Ei olnud seda, kes mind oleks juhatanud. Siis tuli Jeesus nii rohke ja õndsa rõõmoga nagu jõgi, mis langeb ühe kuiva maa pääle. Ma olin jälle Jeesusega ühe valguse sees!

Armsad vennad! Kõige selle raske häda ja kange ministuse sees, et see mulle sel tunnil küll hinge rõõmoks muudeti, mina nägin maapealsed asjad. Ei need olnud kallid ega ei omaksed ega suguvõsa, ei isa ega ema, ei naine ega lapsed, sest need on Jumalast loodud meist maha jääma. Otsekui joomaaeg janu ära ajab, nõnda lõpetavad igavesed taevased Jumala armuannid, uued valgused, lõpmata inglite laulod kõik seda ära, mis maa pääl meile armas ja kallim oli.

Ma nägin ennast jälle uuesti Kristusega olevat kui pruudi oma peigmehele omaks jäänud. Ma olin temaga kui sülelaps oma armsa emaga. Ma nägin ennast jälle kui oma kodu olevat. Siis ma olin valges riides. Ma nägin siis kaks oma armastajat, kuidas nende südamed mure sees mo surma pärast põlesid. Mo armsa ema teretamise hääl, see mõetus veel mu hinge sisse, kui ta mind tuli otsekui viimist korda teretama oma armsa käeandmisega. Ei kõige selle ministuse ja selgeste vaimo silmadega surma ära nähtud juba mööda minevat kõik nende armastuse ja mure [?]. Ei see teinud mulle enam muret ega hingeahastust, sest mulle oli Jumal varaks jäänud. 
Ma nägin äkitselt ennast ühe uue valguse sees, kus ma jälle Kristusega olin. Meie olime jälle selle taevatee pääl, kus meie esmalt üles läksime. Ja siis seal üeldi mulle, et sa jääd veel maa pääle elama. Ma nägin siis ühe teise surevat ja õndsaks mo asemele saavat. Seepärast ma ütlesin ka esimese keele lahtipääsmises: «Kus ma nüüd lähen, teine läks mo asemele taevasse!» Ja mulle üeldi, et Jumal jätkab nüüd veel armust sulle elo. Ma nägin jälle Jeesust seisvat enese kõrvas, ja kaks nagu ingli sarnatsed need olid ja talutasid mind teine teisel käel. Ma nägin veel ühe suure kiriku, kus ma mitte sisse saanud, sest mu hing teadis, et ma veel maa pääle pean jääma elama. Ma nägin ennast siin ja seal olevat, mis ma ei või üles rääkida.

Oh kes saab lihakeelega üles rääkida taevased asjad, mis vaim näeb, kui tema ihust on ära lahkunud. Oh minu süda, kui suureks peaksid sa oma patuhäda tundma ja Kristust kummardades tänama, kes sind nõnda armastanud, et Tema armust sind surmast jälle uuesti tagasi elu sisse on toonud.

Vaata siis, kui mulle öeldi, et sa pead jääma veel maa pääle elama, siis ma olin Jeesusega oma iho juures teiste elavate inimeste käte vahelt läbi käimas ja meid ei saanud ükski kinni pidada. Nüüd sündis äkitselt, et ma hakkasin rasket ja kanget hingevalu ja nii kanget janu tundma, et ma mõtlesin, et maa pääl seda enam ei saa ära kustutud. Nüüd mo hing oli juba iho sees. Ja veel ma nägin sedasama Jeesust siis, kui ma tundsin, et ma iho sees olin, mis ma ennemalt nägin, kui ma ennast nägin surnud olevat. Ta oli inimese näol. Ma nägin ennast Jeesuse najal seisvat, kui ma kange valuga ja tulise janoga pidin surema. Ta näitis veel mulle, otse nago ihosilmad oleksid näinud: Jumala suurest armust antakse sulle veel eloaega patust pöörda, kui sa mõistad seda Kristuse kallist kannatamist ja surma ning vere äravalamist, mis tema armastusest sinu heaks ristipuu peal on kannatanud. Nõnda kõige raskema hingehäda, kurbduse ja valu sees jõuab Jumal rõõmu ja igavest õnnistust anda, kui meie aga Tema armastud ja Kristuse kalli verega ära lunastud ja õndsaks tehtud lapsed oleme. Oh armas Jumal, kui suur ja kartuse väärt oled Sa, kuis ma vaene muld ja põrmuke tohin loota $\mathrm{Su}$ igavese kohtojärje ette seisma jääda, kui mu hinge sees veel ligimese armastust ei ole tunda. Nõnda on vennad: Jumala kohtojärje ette tulles ei maksa änam sugovõsa, ei au ega rikkus, ehk oleks maailm oma rikkuse ja kullaga, ei see ei jõua ühte hinge Kristuse kohtu eest änam ära lunastada. Ei seal muud kui paljas inimene oma hinge ja ihoga peab olema, sest mõtelge - nõnda kui meie üksine ilmale oleme tulnud ja üksine jälle lääme surema, nõnda peab ka Kristuse kohto ette tulema see paljas inimene. Oh mõtle süda, missugune sa siis pead olema, kui need ükski ei aita enam. Ei siis aita enamad kui üsna puhas süda ja kannatlik meel. Kui mina olen näinud, et Jumal üsna heldest armust oli patod andeks annud, oh vennad, Jumala armastud luuliikmed, teile selgest armastusest oma pisut ja hädalist nägemist tääda andma olen võtnud nõuks, et püiaks küll suusõnaga teile head tunnistada[?], ei siiski ma ei suudaks kõike ära mõista ega üles rääkida. Seepärast olgem ustavad ja paluge, et Jumal annaks teile mõista, mis see on - surmast läbi nägema: see on igavest elu siin maa peal uskus ja vaimus ära arvama. Missuguse südamega meie Jumalat ja Taevast õnnistust, uut Jeruusalemma kätte saame. Aamen.

Seda, vennad uskus, arvan mina, et mul ei ole tarvis teile kinnitada, et see tõsi, sest teie usute muidogi, et see tõsi. Aamen, halleluuja. Aamen, halleluuja.

Oh mis rõõm tuleb mino südamesse iga kord, kui see suur ja kallis arm mino meele tuleb, mis head see kallis ja püha, püha, püha Jumal oma armsa ja ainosündinud poja läbi meile on saatnud! Arvame seda südamest järele, mino armad sõbrad: missugune oleks loomade [= 
loodute, loodud olendite] seast taevas või maa peäl olnud, kes seda suurt ja kallist lunastamise tööd oleks võinud korda saata, mis meie esimesed vanemad olid juba paradiisi aedas eksinud, siit saadik ja veel maailma otsani saavad eksima. Ja siis on leitud üks suur ja kallis mees, kel oli üks võti. Kui tema kinni pani, ükski ei teinud lahti, ja kui tema lahti tegi, ükski ei pannud ei taevas, ei maa peäl, ei ka maa all seda enam kinni. Ja kes see mees oli. See oli meie suur lunastaja Jeesus Kristus, kes oma liha päevil madalas põlves kolmkümmend ja kolm [?] aastad siin on elanud, siis on tema jälle oma isamaale tagasi läinud taevasse. See on meie ülempreester, kes meie pato süü ja võlad omas ihos on kannud üles ristipuu pääle ja on meid sest ristist ja needmisest ja surmast ära päästa saand valoga.

See on lõpetud. [- - - ?]

Mina olen sündinud 1779. aastal. Mina olin lugemas 1797. aastal. Ja kui mina abielo sisse astusin - 1798. Ja kui ma leseks sain - 1801 .

Ja kui ma jälle abielo sisse astusin - 1803. Ja mu naine Mari oli vana 23 ja suri.

Ja mo naine Els on vana 20 aastad.

Ja see on lõpetud 1803. aastal ja jaanikuu 7 memal päeval.

E $53896-53909$. 